\title{
Silver lead borate glasses doped with europium ions for phosphors applications
}

\author{
K KESHAVAMURTHY and B ERAIAH* \\ Department of Physics, Bangalore University, Bangalore 560056, India \\ *Author for correspondence (eraiah@rediffmail.com)
}

MS received 18 May 2016; accepted 14 September 2016; published online 25 July 2017

\begin{abstract}
Europium $\left(\mathrm{Eu}^{3+}\right)$ doped silver lead borate glasses with the composition of $x \mathrm{Eu}_{2} \mathrm{O}_{3}-(1-x) \mathrm{Ag}_{2}$ $\mathrm{O}-29 \mathrm{PbO}-70 \mathrm{~B}_{2} \mathrm{O}_{3}(x=0,0.1,0.2,0.3,0.4$ and $0.5 \mathrm{~mol} \%)$ have been successfully prepared by conventional melt quenching method. Thermal, structural and luminescence properties have been studied using thermograms, transmittance, excitation and emission spectra. From the differential scanning calorimetry studies, the glass transition temperatures $\left(T_{\mathrm{g}}\right)$ have been investigated and their values are ranging from 449 to $458^{\circ} \mathrm{C}$. The investigation of Fourier transformer infrared spectra shows the presence of boron atoms in both $\mathrm{BO}_{3}$ and $\mathrm{BO}_{4}$ units in the glass network. In addition, it was found that new structural groups were present, such as boroxyl rings, pyro and dipenta-borate. Photoluminescence spectroscopy was used to examine down conversion emission under $394 \mathrm{~nm}$ excitation, which exhibits five emission bands centred at $577,590,612,650$ and $697 \mathrm{~nm}$ corresponding to ${ }^{5} \mathrm{D}_{0}-{ }^{7} \mathrm{~F}_{0},{ }^{5} \mathrm{D}_{0}-{ }^{7} \mathrm{~F}_{1},{ }^{5} \mathrm{D}_{0}-{ }^{7} \mathrm{~F}_{2},{ }^{5} \mathrm{D}_{0}-{ }^{7} \mathrm{~F}_{3}$ and ${ }^{5} \mathrm{D}_{0}-{ }^{7} \mathrm{~F}_{4}$ transitions of $\mathrm{Eu}^{3+}$ ions, respectively. The Commission International de I'Eclairage France 1931 chromaticity coordinates estimated from the emission spectra; it was shown that a $0.5 \mathrm{~mol} \% \mathrm{Eu}_{2} \mathrm{O}_{3}$ doped glass is quite suitable for efficient red phosphors application.
\end{abstract}

Keywords. Lead borate; DSC; FTIR; photoluminescence.

\section{Introduction}

In recent years, there is an emerging research that focuses on the rare earth (RE) doped oxide glasses due to their potential applications in various fields such as solid-state laser, optical amplifier, display and photo-electronic devices [1,2]. Among the $\mathrm{RE}$ ions, trivalent europium $\left(\mathrm{Eu}^{3+}\right)$ is considered as the most favourable element because of its narrow emission band producing monochromatic light, a long radiative lifetime [3] and the $\mathrm{Eu}^{3+}$ ions doped glasses show interesting emission spectra under near UV excitation. The visible luminescence of the $\mathrm{Eu}^{3+}$ ions doped glasses mainly consists of two eminent intense peaks in the orange $\left(590 \mathrm{~nm} ;{ }^{5} \mathrm{D}_{0}-{ }^{7} \mathrm{~F}_{1}\right.$ transition) and in the red $\left(615 \mathrm{~nm} ;{ }^{5} \mathrm{D}_{0}-{ }^{7} \mathrm{~F}_{2}\right.$ transition) wavelength regions [4]. The red wavelength region is the hypersensitive transition and strongly influenced by the environment around the ions, these kinds of $\mathrm{Eu}^{3+}$ doped glasses find wide range of applications in the field of an efficient red phosphor in particularly designing mercury-fluorescent lamps, LEDs and plasma displays. Glasses containing silver have been technologically interesting materials for solidstate batteries and electrochemical devices because of their valuable optical properties and high value of ionic conductivity [5]. Lead borate glasses are a research interest, owing to their structural peculiarities. The addition of $\mathrm{PbO}$ into the borate network brings modification of boroxol rings and formation of complex groups with one or two four-fold co-ordinated boron atoms [6]. Lead borate glasses have several applications including radiation shields, optical and thermal properties [7,8]. Moreover, borate glasses having high phonon energies, which can be reduced by the addition of $\mathrm{PbO}$ into the borate network makes a reduction in non-radiative loss; thereby causing an enhancement in the luminescence efficiency [9].

In our previous work, we reported that the addition of $\left(\mathrm{Eu}^{3+}\right)$ ions into the silver lead borate glass matrix produces structural modification in the glass network, which leads to significant changes in the optical properties of the glass system [10]. In the present research, the authors intend to study the luminescence properties of the studied glasses through photoluminescence (PL) spectroscopy. The luminescence colour of the glass system excited at $394 \mathrm{~nm}$ has been demonstrated by the Commission International de I'Eclairage France (CIE) 1931 chromaticity diagram. We also studied the thermal and structural properties through differential scanning calorimetry (DSC) and Fourier transformer infrared (FTIR) spectroscopy, respectively.

\section{Experimental}

The raw materials of reagent grade chemicals $\mathrm{H}_{3} \mathrm{BO}_{3}, \mathrm{PbO}$, $\mathrm{Ag}_{2} \mathrm{O}$ and $\mathrm{Eu}_{2} \mathrm{O}_{3}$ were used to synthesize the glass samples by conventional melt quenching method with the composition of 
$x \mathrm{Eu}_{2} \mathrm{O}_{3}-(1-x) \mathrm{Ag}_{2} \mathrm{O}-29 \mathrm{PbO}-70 \mathrm{~B}_{2} \mathrm{O}_{3}(\mathrm{x}=0,0.1,0.2,0.3$, 0.4 and $0.5 \mathrm{~mol} \%)$. The detailed experimental procedure for preparation of glass is given elsewhere [10]. The glass transition temperature $\left(T_{\mathrm{g}}\right)$ was determined by DSC at nitrogen atmosphere in a Perkin Elmer's DSC-6000 in the temperature range $100-500^{\circ} \mathrm{C}$. The FTIR spectra of powdered glass was recorded at room temperature by Nicolet spectrometer with a resolution of $0.2 \mathrm{~cm}^{-1}$ in the frequency range $400-4000 \mathrm{~cm}^{-1}$ by using the standard $\mathrm{KBr}$ pellet method. The excitation and emission spectra was recorded using F-2700 FL spectrophotometer with xenon flash lamp as a source.

\section{Result and discussion}

The DSC patterns for different composition glasses are shown in figure 1 , for a heating rate of $5^{\circ} \mathrm{C} \mathrm{min}^{-1}$ and their obtained values are presented in table 1 . It can be seen from figure 1 that all glass samples showed an endothermal peak, which shifts to lower temperature by adding $0.1 \mathrm{~mol} \%$ of $\mathrm{Eu}_{2} \mathrm{O}_{3}$ and by further increasing the concentration of $\mathrm{Eu}_{2} \mathrm{O}_{3}$ up to $0.5 \mathrm{~mol} \%$, the glass $T_{\mathrm{g}}$ increases linearly. We are well aware

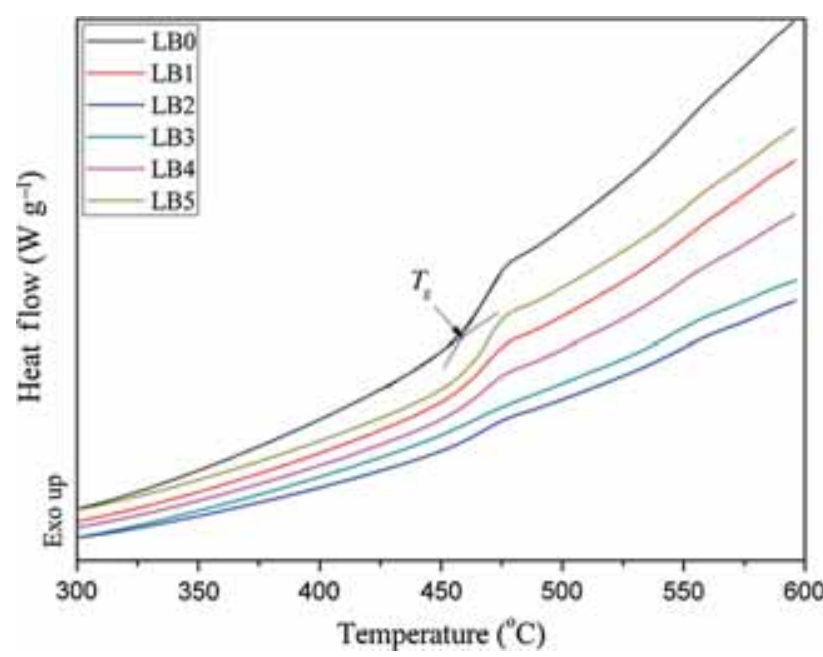

Figure 1. DSC thermograms of the $\mathrm{Eu}_{2} \mathrm{O}_{3}-\mathrm{Ag}_{2} \mathrm{O}-\mathrm{PbO}-\mathrm{B}_{2} \mathrm{O}_{3}$ glass system. that the glass $T_{\mathrm{g}}$ is rigorously linked to the density of crosslinking and bond strength. It is clear that when a higher density of cross-link and higher bond strength of the structure are obtained because of the incorporation of the dopant; the mean bond strength and network connectivity increases, resulting in the increase in glass $T_{\mathrm{g}}$ [11]. When the thermograms of all the samples were re-measured from cooled down to room temperature, the same kind of endothermal peak reappeared for all samples. These results confirm that the first measured glass $T_{\mathrm{g}}$ was not permanent, but reversible. From the DSC results we conclude that the rigidity of glasses increases with the increase in $\mathrm{Eu}_{2} \mathrm{O}_{3} \mathrm{~mol} \%$ from 0.2 to $0.5 \mathrm{~mol} \%$.

The FTIR spectra of the glass system as depicted in figure 2 and their assignments of the bands are presented in table 2 . The broad composite band extending from 3200 to $3600 \mathrm{~cm}^{-1}$ is attributed to hydroxyl $(\mathrm{OH})$ or water group [12]. The broad water bands have been classified into three categories: (i) the peak around $3600-3750 \mathrm{~cm}^{-1}$ is originating from OH-groups, (ii) the peak from 3200 to $3500 \mathrm{~cm}^{-1}$ is originating from the molecular water and (iii) the peak from 2700 to $3000 \mathrm{~cm}^{-1}$ is originating from hydrogen bonding. In figure 2, it can be seen that a strong broad band appeared in the range of $1346-1377 \mathrm{~cm}^{-1}$, which is attributed to $\mathrm{B}-\mathrm{O}$ asymmetric stretching of the trigonal $\mathrm{BO}_{3}$ unit and the shoulder at $1234 \mathrm{~cm}^{-1}$ may arise from $\mathrm{B}-\mathrm{O}$ stretching vibrations of $\left(\mathrm{BO}^{3}\right)^{3-}$ units in metaborates, pyroborates and orthoborates [13]. Similarly the bands around $1087-1113 \mathrm{~cm}^{-1}$ is because of the vibration of some boron atoms attached to non-bridging oxygen in the form of $\mathrm{BO}_{4}$ units [14] and the absorption peaks around $1087-1113 \mathrm{~cm}^{-1}$ is attributed to the formation of diborate in the glass system. The absorption peaks were around $947-971 \mathrm{~cm}^{-1}$ probably due to the stretching vibrations of tetrahedral $\mathrm{BO}_{4}$ units and the band at $993 \mathrm{~cm}^{-1}$ in the spectra may also be assigned to a stretching vibration of $\mathrm{B}-\mathrm{O}-\mathrm{Pb}$ linkage. The band, which is around $710 \mathrm{~cm}^{-1}$ is assigned to bond bending vibrations of $\mathrm{B}-\mathrm{O}-\mathrm{B}$ linkages of the boronoxygen network [12]. The absorption band at $692 \mathrm{~cm}^{-1}$ is assumed to be due to combined vibration of $\mathrm{BO}_{4}$ and $\mathrm{PbO}_{4}$ groups and the band, which is around $699 \mathrm{~cm}^{-1}$ indicates that oxygen bridges two trigonal boron atoms. The spectral domain $400-760 \mathrm{~cm}^{-1}$ is dominated by the band centred at

Table 1. The glass samples composition with glass transition temperature $\left(T_{\mathrm{g}}\right)$ for $\mathrm{Eu}_{2} \mathrm{O}_{3}-\mathrm{Ag}_{2} \mathrm{O}-\mathrm{PbO}-\mathrm{B}_{2} \mathrm{O}_{3}$ glass system.

\begin{tabular}{llllll}
\hline & \multicolumn{4}{c}{ Glass composition (mol\%) } & Glass transition temperature \\
\cline { 2 - 4 } Glass code & $\mathrm{Eu}_{2} \mathrm{O}_{3}$ & $\mathrm{Ag}_{2} \mathrm{O}$ & $\mathrm{PbO}$ & $\mathrm{B}_{2} \mathrm{O}_{3}$ & 70 \\
\hline LB0 & 0 & 1 & 29 & 70 & 456 \\
LB1 & 0.1 & 0.9 & 29 & 70 & 449 \\
LB2 & 0.2 & 0.8 & 29 & 70 & 454 \\
LB3 & 0.3 & 0.7 & 29 & 70 & 455 \\
LB4 & 0.4 & 0.6 & 29 & 70 & 457 \\
LB5 & 0.5 & 0.5 & 29 & 458 \\
\hline
\end{tabular}




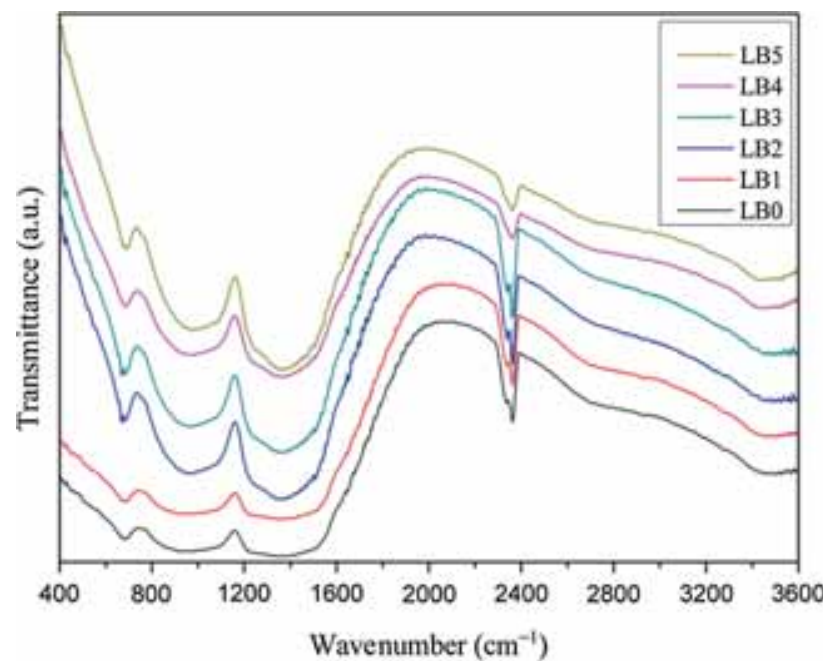

Figure 2. FTIR spectra of the $\mathrm{Eu}_{2} \mathrm{O}_{3}-\mathrm{Ag}_{2} \mathrm{O}-\mathrm{PbO}-\mathrm{B}_{2} \mathrm{O}_{3}$ glass system.

Table 2. Wavenumbers and their assignments for FTIR spectra of the $\mathrm{Eu}_{2} \mathrm{O}_{3}-\mathrm{Ag}_{2} \mathrm{O}-\mathrm{PbO}-\mathrm{B}_{2} \mathrm{O}_{3}$ glass system.

\begin{tabular}{|c|c|}
\hline $\begin{array}{l}\text { Wavenumber } \\
\left(\mathrm{cm}^{-1}\right)\end{array}$ & Assignments \\
\hline $3600-3750$ & OH- group \\
\hline $3200-3500$ & Molecular water \\
\hline $2700-3000$ & Hydrogen bonding \\
\hline $1346-1377$ & $\begin{array}{l}\mathrm{B}-\mathrm{O} \text { asymmetric stretching of trigonal } \\
\mathrm{BO}_{3} \text { unit }\end{array}$ \\
\hline 1234 & $\begin{array}{l}\mathrm{B}-\mathrm{O} \text { stretching vibrations of }\left(\mathrm{BO}^{3}\right)^{3-} \\
\text { units in metaborates, pyroborates and } \\
\text { orthoborates }\end{array}$ \\
\hline 993 & Stretching vibration of $\mathrm{B}-\mathrm{O}-\mathrm{Pb}$ linkage \\
\hline 710 & $\begin{array}{l}\text { Bending vibrations of } \mathrm{B}-\mathrm{O}-\mathrm{B} \text { linkages of } \\
\text { the boron-oxygen network }\end{array}$ \\
\hline 670 & $\begin{array}{l}\mathrm{Pb}-\mathrm{O} \text { bond vibrations and } \mathrm{O}-\mathrm{B}-\mathrm{O} \text { bond } \\
\text { bending vibrations }\end{array}$ \\
\hline
\end{tabular}

$670 \mathrm{~cm}^{-1}$, which is attributed to $\mathrm{Pb}-\mathrm{O}$ bond vibrations and $\mathrm{O}-\mathrm{B}-\mathrm{O}$ bond bending vibrations [15]. It was detected that there was no characteristic vibration of modes of bonds from $\mathrm{Eu}_{2} \mathrm{O}_{3}$ and $\mathrm{Ag}_{2} \mathrm{O}$ oxides in the FTIR spectra.

The down conversion (fluorescence) property of $\mathrm{Eu}^{3+}$ ions in silver lead borate glass was examined. The excitation spectra of $\mathrm{Eu}^{3+}$ was monitored at $\lambda_{\text {em }}=590$ and $612 \mathrm{~nm}$ of ${ }^{5} \mathrm{D}_{0}-{ }^{7} \mathrm{~F}_{1}$ and ${ }^{5} \mathrm{D}_{0}-{ }^{7} \mathrm{~F}_{2}$ transitions that are depicted in figure 3 . The spectral range from 200 to 600 $\mathrm{nm}$ consists of sharp lines, which is attributed to transitions among the $4 \mathrm{f}$ energy levels of $\mathrm{Eu}^{3+}$. The excitation bands can be assigned to $362 \mathrm{~nm}\left({ }^{7} \mathrm{~F}_{0}-{ }^{5} \mathrm{D}_{4}\right), 381 \mathrm{~nm}\left({ }^{7} \mathrm{~F}_{0}-{ }^{5} \mathrm{G}_{3}\right)$, $394 \mathrm{~nm}\left({ }^{7} \mathrm{~F}_{0}-{ }^{5} \mathrm{~L}_{6}\right), 414 \mathrm{~nm}\left({ }^{7} \mathrm{~F}_{0}-{ }^{5} \mathrm{D}_{3}\right), 465 \mathrm{~nm}\left({ }^{7} \mathrm{~F}_{0}-{ }^{5} \mathrm{D}_{2}\right)$ and $533 \mathrm{~nm}\left({ }^{7} \mathrm{~F}_{0}-{ }^{5} \mathrm{D}_{1}\right)$. All the assigned transition values are in good agreement with excitation values of $\mathrm{Eu}^{3+}$ ions as reported in the literature [16]. The excitation spectra shows the

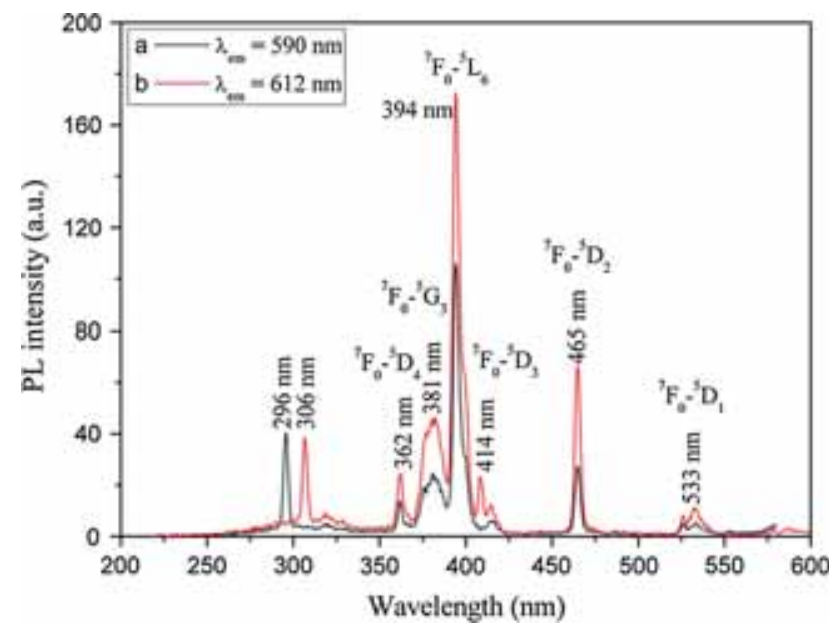

Figure 3. Typical excitation spectra of the $\mathrm{Eu}^{3+}$ glass monitored at $\lambda_{\mathrm{em}}=590$ and $612 \mathrm{~nm}$.

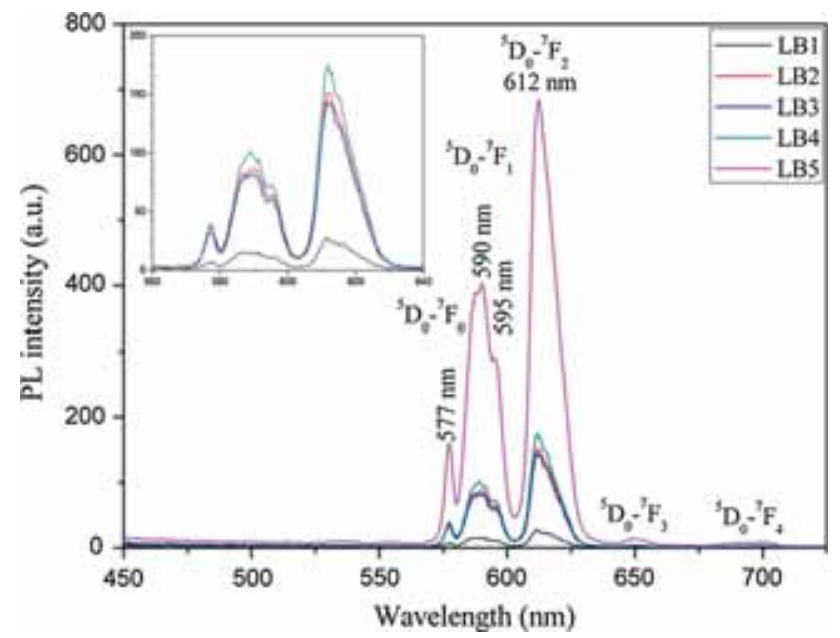

Figure 4. The emission spectra of the $\mathrm{Eu}_{2} \mathrm{O}_{3}-\mathrm{Ag}_{2} \mathrm{O}-\mathrm{PbO}-$ $\mathrm{B}_{2} \mathrm{O}_{3}$ glass system monitored at $\lambda_{\mathrm{ex}}=394 \mathrm{~nm}$.

strongest peak at $394 \mathrm{~nm}$ for $\mathrm{Eu}^{3+}$ and also found peaks at 296 and $306 \mathrm{~nm}$ for $\lambda_{\mathrm{em}}=590 \mathrm{~nm}$ and $612 \mathrm{~nm}$, respectively. A peak shift has been observed from 296 to $306 \mathrm{~nm}$ in the different emission values of $\mathrm{Eu}^{3+}$. Thus, we consider 394, 306 and $296 \mathrm{~nm}$ to be ideal pump wavelengths to generate emission from the prepared samples and the emission spectra shows the most efficient emission peak at $\lambda_{\mathrm{ex}}=394 \mathrm{~nm}$. Figure 4 shows the emission spectra monitored at $\lambda_{\mathrm{ex}}=394 \mathrm{~nm}$ of $\mathrm{Eu}^{3+}$ ions in the glasses. It was clearly seen that the emission spectra consists of a number of peaks in the spectral range 450-725 $\mathrm{nm}$, which corresponds to ${ }^{5} \mathrm{D}_{0}-{ }^{7} \mathrm{~F}_{J}(J=0,1,2,3$ and 4) transitions of $\mathrm{Eu}^{3+}$. In glasses, due to the absence of a centre of symmetry and long-range periodicity of atoms, amalgamation of the $4 \mathrm{f}$ orbitals with an opposite parity orbital takes place [17]. This rise to the electric dipole allowed transitions. The ${ }^{5} \mathrm{D}_{0}-{ }^{7} \mathrm{~F}_{2}$ emission transition is forced by the crystal field 


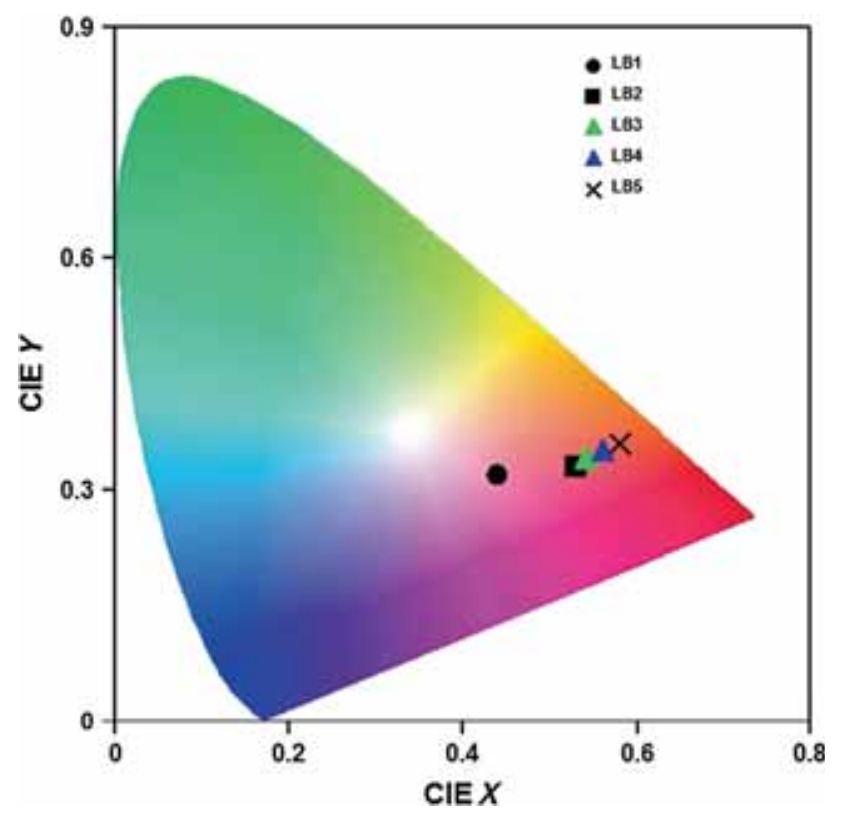

Figure 5. The luminescence colour space chromaticity diagram of the $\mathrm{Eu}_{2} \mathrm{O}_{3}-\mathrm{Ag}_{2} \mathrm{O}-\mathrm{PbO}-\mathrm{B}_{2} \mathrm{O}_{3}$ glass system.

environment in the vicinity of the $\mathrm{Eu}^{3+}$ ions. It is a hypersensitive $(\Delta J=2)$ transition and its intensity is very sensitive to the local environment. The second strongest peak at $590 \mathrm{~nm}$ is in the orange region corresponding to ${ }^{5} \mathrm{D}_{0}-{ }^{7} \mathrm{~F}_{1}$ emission transition (magnetic dipole, $\Delta J=1$ ) of $\mathrm{Eu}^{3+}$ ions, which is spin-forbidden under selection rules. It is allowed due to spin-orbit interaction and its intensity is independent of the host environment. It is also found that in figure 4, there is a small stark splitting at 590 and $595 \mathrm{~nm}$ depending upon the ligand fields being experienced by them and other emissions ${ }^{5} \mathrm{D}_{0}-{ }^{7} \mathrm{~F}_{J}(J=0,3$ and 4$)$ are strictly forbidden and appear with low intensities [18-20]. Among all the emission transitions, the most prominent and intense peak is the one from ${ }^{5} \mathrm{D}_{0}-{ }^{7} \mathrm{~F}_{2}$ transition at $612 \mathrm{~nm}$. As can be seen from figure 4 , an increase in the luminescence intensity is observed, with increasing $\mathrm{Eu}_{2} \mathrm{O}_{3}$ concentration up to $0.2 \mathrm{~mol} \%$ and slight decrease of $0.3 \mathrm{~mol} \%$, further increasing the concentration of $\mathrm{Eu}_{2} \mathrm{O}_{3}$ up to $0.5 \mathrm{~mol} \%$, which increases luminescence intensity. The enhanced emission intensities in the glass system suggested that $\mathrm{Eu}^{3+}$ ions possesses lower symmetry and a strong covalent nature of the bonds between the $\mathrm{Eu}^{3+}$ ions and other constituents in the glass network. The intensity distributions of the ${ }^{5} \mathrm{D}_{0}-{ }^{7} \mathrm{~F}_{J}(J=0,1,2,3$ and 4$)$ transition levels depend on the symmetry of the local environment around the $\mathrm{Eu}^{3+}$ ions and its covalence [21]. It can be observed from figure 4 that the optimum dopant concentration of $\mathrm{Eu}^{3+}$ ions in the silver lead borate glass system was about $0.5 \mathrm{~mol} \%$. The PL concentration quenching effect has also been observed in the glass system at $0.3 \mathrm{~mol} \%$ of $\mathrm{Eu}_{2} \mathrm{O}_{3}$. The luminescence intensity slightly reduces as concentration quenching occurs due to the lack of phonon-assisted process. In addition, it may be due to higher symmetry and a lower Eu-O covalence in the glass network. The luminescence colour of the glasses excited at $394 \mathrm{~nm}$ has been demonstrated by the CIE 1931 chromaticity diagram as depicted in figure 5 . The obtained chromaticity coordinates $(x, y)$ for LB1, LB2, LB3, LB4 and LB5 are $(0.44$, $0.32),(0.53,0.33),(0.54,0.34),(0.56,0.35)$ and $(0.58,0.36)$ respectively, which falls in the pink to red light region of CIE 1931 chromaticity diagram. It is observed from figure 5 that the obtained highest chromaticity coordinates $(0.58,0.36)$ of $0.5 \mathrm{~mol} \%$ of $\mathrm{Eu}_{2} \mathrm{O}_{3}$ produce efficient red light. The other coordinates appearing in the pink to red region, can be used as pink to red colour phosphors applications and have several potential applications in photonic devices as well.

\section{Conclusions}

Silver lead borate glasses, doped with $\mathrm{Eu}^{3+}$ trioxide were successfully synthesized by conventional melt quenching method. DSC results concluded that increasing of the rigidity of the glasses occurs with an increase in $\mathrm{Eu}_{2} \mathrm{O}_{3}$ concentration in the host matrix. The investigation of FTIR spectra revealed that in the glass matrix various borate groups are randomly interconnected. We observed the presence of boron atoms in both $\mathrm{BO}_{3}$ trigonal units and $\mathrm{BO}_{4}$ tetrahedral units with new complex structural groups such as diborate, triborate, tetra borate and penta borate units in the glass network. No change was observed in the glass structure with the variation of $\mathrm{Eu}_{2} \mathrm{O}_{3}$ and addition of $\mathrm{Ag}_{2} \mathrm{O}$ in the host matrix. From the PL studies of the glass system it is found to be an intense red emission peak for $0.5 \mathrm{~mol} \%$ of $\mathrm{Eu}^{3+}$ ions, which is suitable for efficient red phosphor applications. However, we found that concentration quenching effect at $0.3 \mathrm{~mol} \%$ of $\mathrm{Eu}^{3+}$ ions is because of the lack of phonon-assisted process. The CIE 1931 chromaticity coordinates $x$ and $y$ were found to be in the pink to red light region. These kinds of luminescence functionality novel phosphor glasses are promising materials for practical applications in mercury-fluorescent lamps, LEDs and plasma displays.

\section{Acknowledgement}

We would like to thank the University Grants Commission, New Delhi, India, for the financial support through Major Research Project (F.No. 41-938/2012).

\section{References}

[1] Salavcova L, Mackova A, Oswald J, Svecova B, Janakova S and Spirkova J 2007 J. Phys. Chem. Solids 68891

[2] Li Y Z, Zhang Q Y, Shi D M, Qian Q and Xu S H 2009 Opt. Mater. (Amst) 32334

[3] Hatefi Y, Shahtahmasebi N, Moghimi A and Attaran E $2010 \mathrm{~J}$. Lumin. 131114

[4] Kiran N 2014 J. Mol. Struct. 1065-1066 93 
[5] Jiménez J A, Lysenko S, Liu H, Eachini E and Cabrera C R 2010 J. Lumin. 130163

[6] Alemi A A, Sedghi H, Mirmohseni A R and Golsanamlu V 2006 Bull. Mater. Sci. 2955

[7] Limkitjaroenporn P, Kaewkhao J, Limsuwan P and Chewpraditkul W 2011 J. Phys. Chem. Solids 72245

[8] Kashif I, Abd El-Maboud A and Ratep A 2014 Results Phys. 41

[9] Swapna K, Mahamuda S, Srinivasa Rao A, Shakya S, Sasikala T, Haranath D et al 2014 Spectrochim. Acta A Mol. Biomol. Spectrosc. 12553

[10] Keshavamurthy K and Eraiah B 2015 Bull. Mater. Sci. 381381

[11] Shih P Y 2002 Mater. Chem. Phys. 80299

[12] Singh D, Singh K, Singh G, Mohan S, Arora M and Sharma G 2008 J. Phys. Condens. Matter 20075228

[13] Kamitsos E I, Chryssikos G D and Karakassides M A 1987 J. Phys. Chem. Solids 911067
[14] Motke S G, Yawale S P and Yawale S S 2002 Bull. Mater. Sci. 2575

[15] Balachander L, Ramadevudu G, Shareefuddin M, Sayanna R and Venudhar Y C 2013 ScienceAsia 39278

[16] Hreniak D, Jasiorski M, Maruszewski K, Kepinski L, Krajczyk L, Misiewicz J et al 2002 J. Non-Cryst. Solids 298 146

[17] Arunkumar S, Venkata Krishnaiah K and Marimuthu K 2013 Phys. B Condens. Matter 41688

[18] Dejneka M, Snitzer E and Riman R E 1995 J. Lumin. 65 227

[19] Venkatramu V, Navarro-Urrios D, Babu P, Jayasankar C K and Lavín V 2005 J. Non-Cryst. Solids 351929

[20] Babu P, Jang K H, Kim E S, Vijaya R, Jayasankar C K, Lavín $\mathrm{V}$ et al 2011 J. Non-Cryst. Solids 3572139

[21] Swapna K, Mahamuda S, Rao A S, Sasikala T, Packiyaraj P, Moorthy L R et al 2014 J. Lumin. 15680 